\title{
Numerical analysis of weld penetration geometry during gas tungsten arc welding considering influence of metal vapor mixture
}

\author{
K. Yamamoto, M. Tanaka, S. Tashiro, K. Nakata, and A. B. Murphy* \\ Joining and Welding Research Institute, Osaka University, 11-1 Mihogaoka, Ibaraki, Osaka 576-0047 \\ Fax: 81-06-6879-8689, e-mail: k-yama@jwri.osaka-u.ac.jp \\ * Materials Sci. and Eng., CSIRO, PO Box 218, Lindfield NWS 2070, Australia
}

\begin{abstract}
A gas tungsten are in helium is modeled taking into account the contamination of the plasma by the metal vapor from the weld pool surface. The whole region of gas tungsten arc welding, namely the tungsten cathode, arc plasma and weld pool, is treated using a unified numerical model. A viscosity approximation is used to express the diffusion coefficient in terms of the viscosities of the helium gas and the iron vapor. The two-dimensional distributions of temperature, velocity and iron vapor concentration are predicted, together with the weld penetration at atmospheric pressure. It is shown that the thermal plasma in gas tungsten arcs is markedly influenced by iron vapor from the weld pool surface.

Key words: Simulation, Arc, Metal vapor, Weld penetration
\end{abstract}

\section{INTRODUCTION}

During the arc welding process, four states of matter, solid, liquid, gas and plasma, simultaneously exist and mutually interact within a volume of only $1 \mathrm{~cm}^{3}$. The temperature range is wide, ranging from about $20000 \mathrm{~K}$ in the arc plasma, about $3000 \mathrm{~K}$ in the tungsten cathode, about $2000 \mathrm{~K}$ in the molten steel, down to room temperature in the surrounding regions [1]. Due to the remarkable progress in computer simulation and observation techniques recently, it has become possible to understand the phenomena in arc welding processes quantitatively $[2,3]$. However, it has not been possible to accurately predict the welding parameters, such as the arc voltage and the weld geometry. For a full understanding and accurate prediction of these parameters, it is necessary to understand the behavior of metal vapor in the are plasma.

Metal atoms generally have more low-energy excited states, and are more easily ionized, than atoms of shielding gases such as argon and helium. These characteristics contribute to an increase of the radiative emission coefficient and the electric conductivity of the plasma. It is estimated that the former affects the thermal pinch effect and the energy efficiency of the arc plasma and that the latter affects the current density distribution. Tashiro et al. [4] conducted a virtual experiment by numerical simulating a pure helium arc and an are in helium uniformly mixed with $30 \mathrm{~mol} \%$ iron atoms, and showed that an obvious arc constriction occurred for the latter case. Furthermore, they reported that the energy efficiency greatly decreased from about $80 \%$ to about $35 \%$. These results suggested that existence of metal vapor changed the heat source property in the arc welding process, and consequently changed the size and the shape of the molten pool.

As noted above, there have been significant advances in the simulation of the are welding. Most early numerical models have treated either only the arc plasma $[5,6]$ or only the weld pool $[7-10]$ without metal vapor consideration. Recently, the completely unified model of gas metal arc with the formation of droplets from a steel wire electrode and also the weld pool has been reported [2] However, the welding gas was pure argon, and the effect of metal vapor was not considered. On the other hand, calculations of the behavior of metal vapor in an atmospheric pressure plasma have also been reported [11]. However, the conditions were far from those of welding because a solid electrode with constant temperature was assumed. It is important for accurate understanding of the arc welding process to consider the mixing of the metal vapor in a model that takes into account the tungsten cathode, the arc plasma and the weld pool.

In the present paper, we use a numerical model of stationary GTA welding taking into account the iron vapor produced from the weld pool surface, and we simulate the distribution of the metal vapor, the plasma temperature and the formation of the weld pool in GTA welding.

\section{SIMULATION MODEL}

The tungsten cathode, arc plasma and anode are described relative to cylindrical coordinates, assuming rotational symmetry around the arc axis. The calculation domain is shown in Fig. 1. The diameter of the tungsten cathode is $3.2 \mathrm{~mm}$ with a 60 degrees conical tip. The arc gap is set to be $3 \mathrm{~mm}$, $5 \mathrm{~mm}$ or $7 \mathrm{~mm}$. The anode is of stainless steel. Top of the cathode and bottom of the anode are set to be $300 \mathrm{~K}$. Helium shielding gas is introduced from the outside of the cathode on the upper boundary at the flow rate of $30 \mathrm{~L} / \mathrm{min}$. The flow is assumed to be laminar, and arc plasma is assumed to be in local thermodynamic equilibrium (LTE). Furthermore, the anode surface is assumed to be flat and unperturbed by the arc pressure. The governing equations, such 


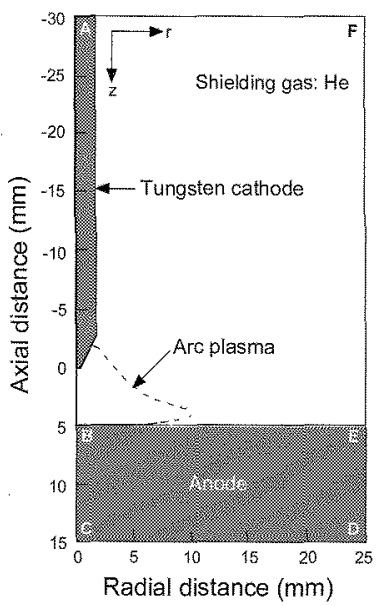

Fig. 1 Schematic illustration of simulation domain (Arc gap: $5 \mathrm{~mm}$ ).

as the mass continuity equation, the momentum conservation equation, energy conservation equation and the current continuity equation, and boundary conditions are given in detail in our previous papers $[4,13]$. The governing and auxiliary equations are solved iteratively by the SIMPLEC numerical procedure. Only the most pertinent points are explained here.

The convection in the weld pool is influenced by the shear stress due to the convective flow of the cathode jet, the Marangoni force due to the gradient in the surface tension of the weld pool, buoyancy due to gravity and the electromagnetic pinch force due to the arc current. Only the driving forces of the weld pool convection at the boundary between the weld pool and the are plasma are explained here. First, the shear stress is already included in radial momentum conservation through the viscosity at the anode surface. Second, the Marangoni force is given by [12]

$$
M_{A}=\frac{\partial}{\partial z}\left(\frac{\partial \gamma}{\partial T} \frac{\partial T}{\partial r}\right)
$$

where $T$ is temperature, $\gamma$ is the surface tension of the weld pool. In this paper, stainless steel is assumed to have low sulfur content (about $10 \mathrm{ppm}$ ) and the variation of the surface tension at the weld pool surface is assumed to decrease linearly with increasing temperature $(\partial \gamma / \partial T=-0.46 \mathrm{mN} / \mathrm{mK})$ [12].

A species conservation equation expressed by Eq. (2) is applied to take into account the metal vapor behavior [11]. In practice, metal vapor species in an arc plasma with a stainless steel anode include $\mathrm{Fe}$, $\mathrm{Cr}, \mathrm{Ni}, \mathrm{Mn}$ and so on [13]. However, to simplify the model and facilitate calculation, only iron vapor is considered in this model.

$$
\begin{aligned}
\frac{1}{r} \frac{\partial}{\partial r}\left(r \rho v_{r} C_{1}\right) & +\frac{\partial}{\partial z}\left(\rho v_{z} C_{1}\right) \\
= & \frac{1}{r} \frac{\partial}{\partial r}\left(r \rho D \frac{\partial C_{1}}{\partial r}\right)+\frac{\partial}{\partial z}\left(\rho D \frac{\partial C_{1}}{\partial z}\right)
\end{aligned}
$$

where $v_{r}$ and $v_{z}$ are the radial and axial velocities, $\rho$ is the density, $C_{1}$ is mass fraction concentration of iron vapor and $D$ is the binary diffusion coefficient, which is expressed by the viscosity approximation equation:

$$
D=\frac{2 \sqrt{2}\left(1 / M_{1}+1 / M_{2}\right)^{0.5}}{\left.\left(\rho_{1}^{2} / \beta_{1}^{2} \eta_{1}^{2} M_{1}\right)^{0.25}+\left(\rho_{2}^{2} / \beta_{2}^{2} \eta_{2}^{2} M_{2}\right)^{0.25}\right]_{2}^{2}}
$$

where $M_{1}$ and $M_{2}$ are the molecular weights of iron and the shielding gas respectively. Similarly, $\rho_{1}$, $\rho_{2}, \eta_{1}, \eta_{2}$ are respectively the density and viscosity of iron and the shielding gas. $\beta_{1}, \beta_{2}$ are the dimensionless constant defined as $\beta_{i}=\left(D_{i i} \rho_{i}\right) / \eta_{i}$, and theoretically range 1.2 to 1.543 for various species of gas, such as $\mathrm{Ar}, \mathrm{He}, \mathrm{H}_{2}, \mathrm{~N}_{2}$, $\mathrm{O}_{2}, \mathrm{CO}_{2}$ and so on. It is assumed that $\beta_{1}=\beta_{2}=1.385$, which is based on the mean value of experimental data [14]. The viscosity approximation is not strictly justified since it does not take into account ionized species and is at best reasonably accurate [15]; however it is considered to be a useful first approximation for the arc welding model.

$C_{1}$ is set to be zero in the cathode area and in the solid area of the anode. However, at the anode surface where the temperature is above the melting point, $C_{1}$ is set to [11]:

$$
C_{1}=\frac{p_{v, 1} M_{1}}{p_{v, 1} M_{1}+\left(p_{a t m}-p_{v, 1}\right) M_{2}}
$$

where $p_{\text {otm }}$ is atmospheric pressure and $p_{v, 1}$ is the iron vapor partial pressure, which is a function of the weld pool temperature [16]. According to Eq. (4), $C_{1}$ has values between zero and 1.0. For other boundary conditions, $C_{1}=0$ at $A F$ and $F E$ shown in Fig. 1, and $\left(\partial C_{1} / \partial r\right)=0$ at the arc axis $(A B)$.

In the present model, plasma properties are dependent on not only the temperature but also the mole fraction of iron vapor. Plasma properties at intermediate concentrations of iron vapor are calculated using a linear approximation based on the properties at $0 \mathrm{~mol} \%, 1 \mathrm{~mol} \%, 10 \mathrm{~mol} \%, 20 \mathrm{~mol} \%$ and $30 \mathrm{~mol} \%$ [17]. The properties are calculated assuming the arc plasma to be in LTE, which are applicable to high intensity arcs $(\mathrm{I}>50 \mathrm{~A})[18]$, and

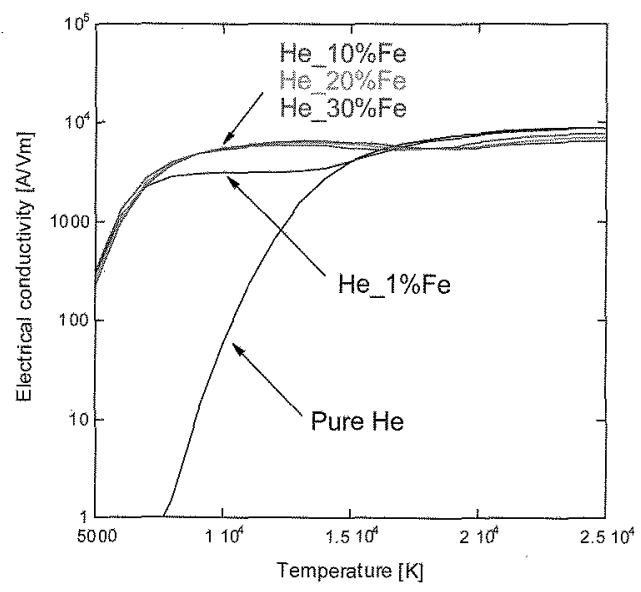

Fig. 2 Dependence of electrical conductivities of helium gas on temperature for each mixing ratio. 
using the Chapman-Enskog approximation [17]. For example, the electrical conductivities, which are significantly affected, are shown in Fig. 2. The electrical conductivities are greatly increased by the addition of iron vapor at temperatures below 15000 $\mathrm{K}$, and the values for mixing ratios $1 \%, 10 \%, 20 \%$ and $30 \%$ are almost the same.

\section{RESULT AND DISUCUSSION}

The present model is applied to the case of stationary helium GTA welding of stainless steel. Fig. 3, 4 and 5 show the two-dimensional distributions of temperature, fluid flow velocity and mole fraction of iron vapor. The distribution of iron vapor depends on the diffusion term and the convection term, as described in Eq. (2). When the are gap is $5 \mathrm{~mm}$ or $7 \mathrm{~mm}$, due to the cathode jet, which leads to flow velocities of over $300 \mathrm{~m} / \mathrm{s}$ in the welding arc, the convection term has a strong effect. Therefore, it is found that distribution of iron vapor expands in the radial direction and is concentrated around the weld pool surface. The concentration of iron vapor in the arc plasma is up to $7 \mathrm{~mol} \%$, which is in good agreement with the experimental data

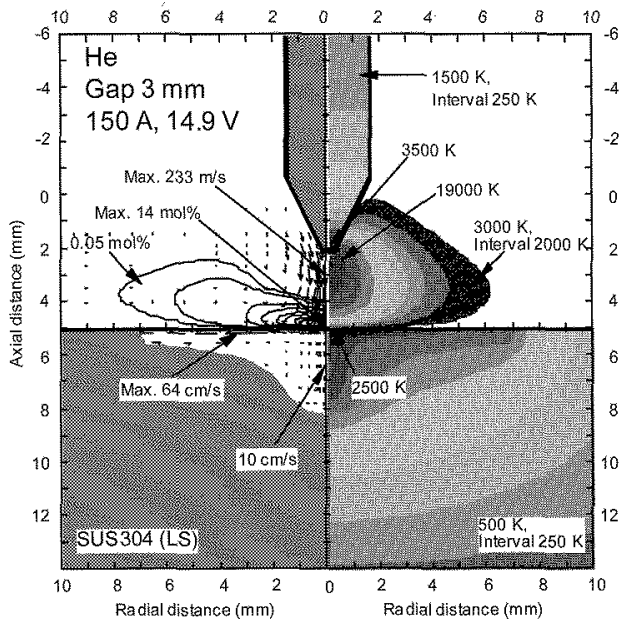

Fig. 3 Calculated results for GTA welding for $150 \mathrm{~A}$ (arc gap: $3 \mathrm{~mm}$ ).

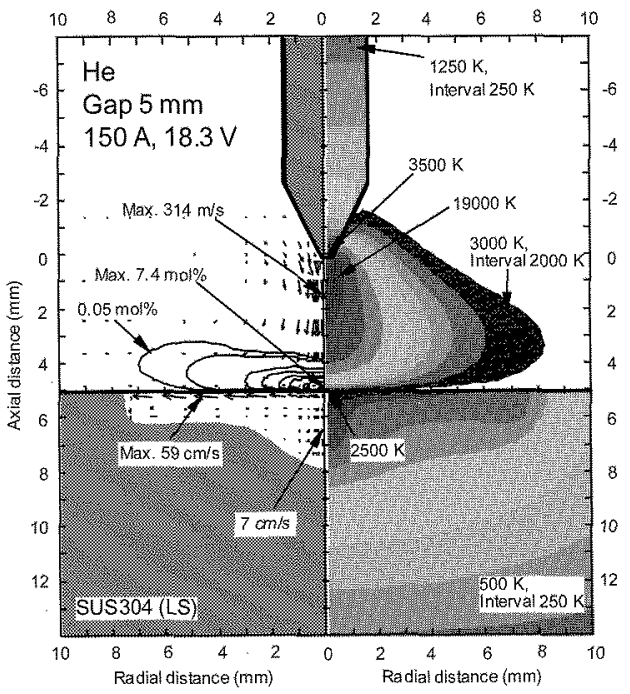

Fig. 4 Calculated results for GTA welding for $150 \mathrm{~A}$ (arc gap: $5 \mathrm{~mm}$ ) presented by Terasaki [13]. When the are gap is 3 $\mathrm{mm}$, the convection term also has a strong effect. However, the cathode jet is slower and distribution of iron vapor expands in the axial direction more than other cases.

Fig. 6 shows the radial distributions of iron vapor concentration on the anode surface. In the case of 3 $\mathrm{mm}$ arc gap, the concentration of iron vapor is up to $13 \mathrm{~mol} \%$ near the arc axis, which is clearly higher than other cases. This is because of the higher weld pool temperature and the lower cathode jet. The maximum pool temperatures for $3 \mathrm{~mm}, 5 \mathrm{~mm}$ and 7 $\mathrm{mm}$ arc gap are $2870 \mathrm{~K}, 2726 \mathrm{~K}$ and $2700 \mathrm{~K}$, respectively. In the cases of $5 \mathrm{~mm}$ and $7 \mathrm{~mm}$ arc gap, the distributions are almost same.

Then, Fig. 7 shows the distributions of temperature and fluid flow velocity for $3 \mathrm{~mm}$ arc gap calculated neglecting the effect of iron vapor on the arc plasma. It is obvious that the weld penetration geometry is clearly different from that considering the effect of iron vapor.

Fig. 8 shows current density distributions at the anode surface. The distributions calculated considering and neglecting the effect of iron vapor

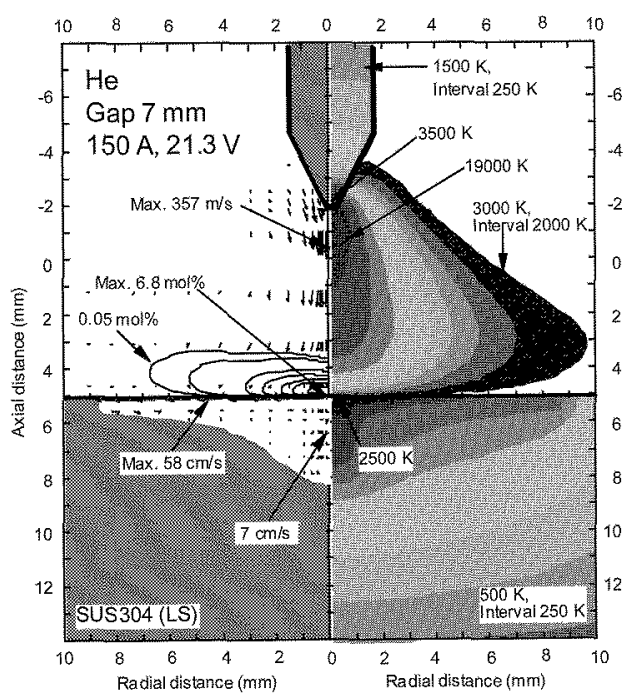

Fig. 5 Calculated results for GTA welding for 150A (arc gap: $3 \mathrm{~mm}$ )

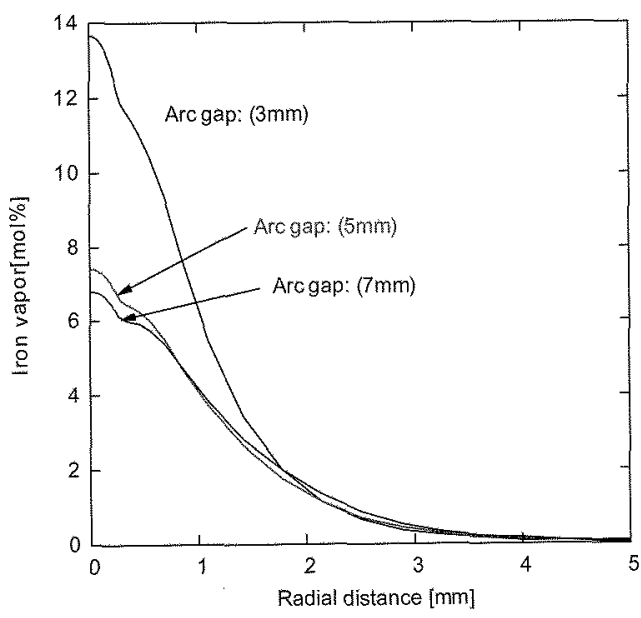

Fig, 6 Radial distributions of iron vapor concentration on the anode. 


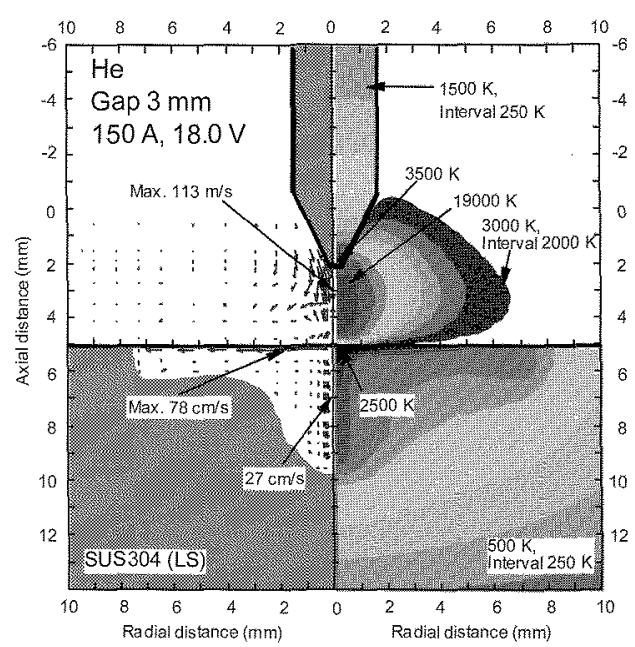

Fig. 7 Calculated results for GTA welding neglecting the effect of iron vapor (arc gap: $3 \mathrm{~mm}$ ).

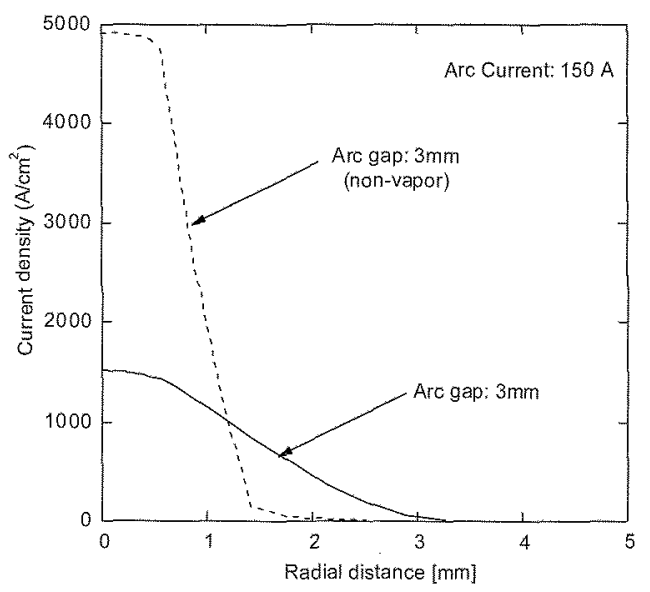

Fig. 8 Comparison of calculated current densities at the anode surface.

on the arc plasma are shown. The peak current density for the latter is about $5000 \mathrm{~A} / \mathrm{cm}^{2}$. The distribution for the former is clearly different. The presence of iron vapor decreases the peak current density to $1500 \mathrm{~A} / \mathrm{cm}^{2}$, and the region through which current flows is expanded by the increase of the electric conductivity at lower temperatures; as shown in Fig. 2, the increase is greater at the lower temperatures that occur away from the arc axis.

\section{CONCLUSIONS}

We have used a numerical model of a stationary GTA welding taking into account the iron vapor from weld pool surface. The main conclusions are summarized as follows:

1) When the arc gap was $5 \mathrm{~mm}$ or $7 \mathrm{~mm}$, due to the cathode jet of over $300 \mathrm{~m} / \mathrm{s}$ in the welding arc, the convection term strongly affected the distribution of the iron vapor and iron vapor expanded mainly in the radial direction. When the arc gap was $3 \mathrm{~mm}$, the distribution of iron vapor expands in the axial direction more than other cases, because of the slower cathode jet.
2) In the case of $3 \mathrm{~mm}$ arc gap, the concentration of iron vapor on the anode is up to $13 \mathrm{~mol} \%$ near the arc axis, which is clearly higher than other cases.

3) The weld penetration geometry calculated neglecting the effect of iron vapor was clearly different from that considering the effect of iron vapor.

4) The arc current distribution calculated taking into account the iron vapor was clearly different from that for calculated neglecting the iron vapor. The peak current density obtained neglecting the iron vapor was about 5000 $\mathrm{A} / \mathrm{cm}^{2}$, while that obtained taking into account the iron vapor decreased to about $1500 \mathrm{~A} / \mathrm{cm}^{2}$. In the latter case, the region through which current flows was expanded by the increase of the electric conductivity at lower temperatures, which was particularly important away from the arc axis.

\section{References}

[1] M. Tanaka, T. Watanabe, T. Isa and H. Nishiwaki: 'New development of welding and thermal spraying', J. Plasma \& Fusion Res., 82-8, 492-496 (2006) (in Japanese).

[2] H.G. Fan and R. Kovacevic: J. Phys. D: Appl. Phys, 37, 2531-2544 (2004).

[3] H. Nishiyama, T. Sawada, H. Takana, M. Tanaka and M. Ushio: ISIJ Int., 46-5, 705-711 (2006).

[4] S. Tashiro, M. Tanaka, K. Nakata, T. Iwao, F. Koshiishi, K. Suzuki and K. Yamazaki: Sci. Technol. Weld. Join., 12-3, 202-207 (2007).

[5] K.C. Hsu, K. Etemadi and E. Pfender: J. Appl. Phys, 54, 1293-1301 (1983).

[6] M. Goodarzi, R. Choo and J.M. Toguri: J. Phys. $D, 30,2744-2756$ (1997).

[7] S.A. David, T. DebRoy and J.M. Vitek: MRS Bull., 19, 29-35 (1994).

[8] T. Zacharia, S.A. David, J.M. Vitek and H.G. Kraus: Weld. J., 74, 353-362 (1995).

[9] W.H. Kim, H.G. Fan and S.J. Na: Numerical Heat Transfer A, 32, 633-652 (1997).

[10] H.G. Fan, H.L. Tsai and S.J. Na: Int. J. Heat Mass Transfer, 44, 417-428 (2001).

[11] J. Menart and L. Lin: Plasma Chem. \& Plasma Process., 19-2, 153-170 (1999).

[12] M. Tanaka and J.J. Lowke: J. Phys. D: Appl. Phys, 40, R1-R23 (2007).

[13] H. Terasaki, M. Tanaka and M. Ushio: Quarterly J. Japan Welding Soc., 20-2, 201-206 (2002).

[14] C.R. Wilke: J. Chem. Phys., 18-4, 517-519 (1950).

[15] A.B. Murphy: J. Phys. D: Appl. Phys, 29, 1922-1932 (1996).

[16] The Japan Institute of Metals: 'Edition No. 3 Data Book of Metals', MARUZEN CO. LTD, Tokyo (1993) (in Japanese).

[17] A.B.Murphy: Plasma Chem. \& Plasma Process., 15-2, 279-307 (1995).

[18] M.N. Hirsh and H.J. Oskam (ed): 'Gaseous Electronics Vol. 1', Academic Press, New York, p351 (1978)

(Recieved December 10, 2007 ; Accepted April 15, 2008) 